\title{
A EDUCAÇÃ̃ SUPERIOR À LUZ DA PRODUÇÃO DO CONHECIMENTO: O CONTEXTO EMERGENTE DOS INSTITUTOS FEDERAIS/BRASIL
}

\author{
THE HIGHER EDUCATION IN THE PRODUCTION OF KNOWLEDGE: \\ THE EMERGING CONTEXT OF FEDERAL INSTITUTES/BRAZIL
}

EDUCACIÓN SUPERIOR EN LA PRODUCCÍON DO CONOCIMIENTO:

EL CONTEXTO EMERGENTE DE LOS INSTITUTOS FEDERAIS/BRAZIL

\begin{abstract}
Julian Silveira Diogo de Ávila Fontoura ${ }^{1}$ Marilia Costa Morosini ${ }^{2}$

RESUMO

A Lei $n^{\circ}$ 11.892/08 trouxe para o Brasil um novo modelo de instituição ensino, responsável por agregar ciência e tecnologia na formação dos cidadãos, de forma a articular em sua proposição diferente níveis e modalidades a Educação Profissional e Tecnológica, incluindo neste a Educação Superior: os Institutos Federais de Educação, Ciência e Tecnologia (IF's). A fim de concretizar o que preconiza a legislação no que se refere a efetivação da Educação Superior neste contexto emergente, nos parece que compreender este novo modelo institucional surge como uma questão relevante para a investigação científica. Nesse sentido, acreditamos que seja interessante identificar quais são os principais enfoques de estudo (objetos), que se apresentam no campo da pesquisa científica para o entendimento deste fenômeno. Este estudo busca identificar a produção acadêmica desenvolvida por diferentes Programas de Pós-Graduação brasileiros, dentro da temática da Educação Superior no contexto dos Institutos Federais de Educação, Ciência e Tecnologia pelo viés da Gestão Educacional entre os anos de 2011 e 2016. Na produção dos dados, utilizamos os princípios de Estado do Conhecimento com foco na pesquisa bibliográfica de abordagem descritiva. Os resultados deste estudo apontam como uma tendência dentro do campo, a percepção da Educação Superior à luz da prática implementada no interior deste novo modelo institucional, onde os aspectos relacionados a efetividade pedagógica e a relevância cultural, se colocam no cerne das pesquisas desenvolvidas, destacando ainda as categorias utilizadas para o entendimento da produção acadêmica sobre a temática da Educação Superior na perspectiva desta nova institucionalidade.
\end{abstract}

PALAVRAS-CHAVE: Educação superior. Gestão educacional. Estado do conhecimento. Institutos federais.

\section{ABSTRACT}

The law of $\mathrm{n}^{\mathrm{o}} 11.892 / 08$ introduced to Brazil a new model of institutional education. This new model adds science and technology to citizens' development by coordinating different levels and modes of such development with profissional and technological education. In such case, higher eduction is also included in the framework: the Federal Institutes of Education, Science and Technology (IF's). In the purpose of realizing the concept that the legislation defends in current higher education context, to comprehend this new institutional model arises as an important issue for scientific researches. Therefore, we believe that it is essencial to identify

\footnotetext{
${ }^{1}$ Professor da Área de Ciências da Natureza do Colégio Estadual Inácio Montanha; Mestrando da Escola de Humanidades da Pontifícia Universidade Católica do Rio Grande do Sul. E-mail: julian.fontoura@acad.pucrs.br - ORCID: http://orcid.org/0000-0001-8507-6538

${ }^{2}$ Doutora em Educação pela Universidade Federal do Rio Grande do Sul. Professora Titular da Escola de Humanidades da Pontifícia Universidade Católica do Rio Grande do Sul. E-mail: marilia.morosini@ pucrs.br ORCID: http://orcid.org/0000-0002-3445-1040

Submetido em: 10-03-2017 / Aceito em: 01-04-2017 / Publicado em: 14-04-2017.
}

\begin{tabular}{l|l|l|l|l|l|l} 
(C) Rev. Inter. Educ. Sup. & Campinas, SP & v.3 & n.1 & p.167-185 & jan./abr. 2017 & ISSN 2446-9424
\end{tabular}


which are the major focuses of researches. Through such studies, we are able to understand more about the phenomenon. The present research seeks to locate academic researches developed by various Brazilian PostGraduation programs within the scope of educational administration, in the context of higher education of Federal Institutes of Education, Science and Technology during 2011 to 2016. In the section of datas, we utilize principles of State of Arts with focus on descriptive approach of biographical research. The outcome of the present research indicates a tendency within the studied field and the perception of implemented practice in higher education within this new institutional model where the related aspects, the pedagogical effectiveness and the cultural relevance are placed in the centre of the researches carried out. It emphasizes, as well, the categories used in current paper in order to comprehend academic works about higher education in the new institutional perspective.

KEYWORDS: College education. Educational management. State of knowledge. Federal institutes.

\section{RESUMEN}

Ley $\mathrm{n}^{\mathrm{o}}$ 11.892/08 trajo a Brasil un nuevo modelo de institución de educación, responsable de la unión de la ciencia y la tecnología en la educación de los ciudadanos, articulado a Educación Profesional y Tecnológica: los Institutos Federales de Educación, ciencia y Tecnología (IF's). Con el fin de lograr lo que denomina la legislación en cuanto a la realización de la educación superior en este contexto emergente, parece importante entender este modelo institucional que emerge como un tema relevante para la investigación científica. Creemos que es interesante identificar cuáles son los principales enfoques de estudio que se presentan en el campo de la investigación científica para la comprensión de este fenómeno. Este estudio busca identificar la producción académica desarrollada por diferentes licenciaturas de Brasil (2011 - 2016), dentro del tema de la educación superior en el contexto de la IF's de desde la perspectiva de la gestión educativa. En la producción de los datos, utilizamos los principios de Estado de Conocimientos centrados en la aproximación descriptiva literatura. Los resultados de este estudio apuntan a una tendencia en el campo de la percepción de la educación superior, a la luz de la práctica implementada dentro de este nuevo modelo institucional, donde los aspectos relacionados con la eficacia educativa y pertinencia cultural, se colocan en el centro de la investigación desarrollada destacando también las categorías utilizadas para la comprensión de la literatura académica sobre el tema de la educación superior en este contexto.

PALABRAS ClAVE: Educación universitaria. Gestión de la educación. Estado del conocimiento. Institutos federales.

\section{INTRODUÇÃ̃o}

No Brasil a Educação Superior acaba centrando-se principalmente na produção do conhecimento, tecnologias e ainda a formação de profissionais de diferentes áreas do conhecimento a fim de atender as demandas oriundas do mundo do trabalho. A Educação Superior nesse sentido acaba respondendo de forma direta a demandas emergentes da formação dos sujeitos já que prioriza, em um primeiro momento "a qualificação do desenvolvimento de estudantes para atuarem em diferentes carreiras, incluindo a de professor, dentre os quais poderão auxiliar na constituição e desenvolvimento da sociedade", como afirma Santos (2014, p. 241). No Brasil, o Ministério da Educação (MEC) é o responsável pela regulamentação da Educação Superior e dos estabelecimentos de Ensino que a ofertam, e nesse conjunto, temos uma série de instituições, como aponta Cavalcante (2000, p. 21), o Sistema Universitário Brasileiro é composto por instituições Universitárias (Universidades Públicas, Privadas e Comunitárias) e Não Universitárias (Faculdades, Centros Federais de Educação Tecnológica, Escolas Superiores e Institutos Superiores). 
E é nesse contexto emergente que situamos nosso estudo, ao final de 2008, a Educação Profissional e Tecnológica (EPT) no Brasil é redesenhada, uma nova concepção do seu papel e suas finalidades são colocadas a prova a partir da criação da Lei $\mathrm{n}^{\circ} 11.892$ promulgada em 29 de dezembro de 2008. A força da lei institui a Rede Federal de Educação Profissional e Tecnológica (RFEPT), modificando o arranjo desta modalidade de ensino, porém a nova legislação propõe mudanças mais profundas do que a reordenação das instituições já existentes pertencentes a Rede de Educação Profissional e Tecnológica (RFEPT), a Lei $\mathrm{n}^{\circ} 11.892$ de 29 de dezembro de 2008, cria uma nova instituição responsável por atender as demandas educacionais advindas do mundo do trabalho, a partir dos princípios de equidade e justiça social: Institutos Federais de Educação, Ciência e Tecnologia (IF’s).

A Lei n ${ }^{\circ} 11.892 / 08$ cria uma nova instituição responsável por agregar ciência, trabalho e tecnologia na construção de cidadãos emancipados e conscientes de seu papel na sociedade, fazendo deste novo modelo de instituição um suporte efetivo para as políticas públicas de transformação social através da educação, ou seja, essa nova instituição acaba atingindo um novo patamar em relação a função social das instituições de ensino, principalmente no que diz respeito a relação imbricada existente entre a Educação Profissional e Tecnológica (EPT) e o Mundo do Trabalho. Essa nova institucionalidade acabou potencializando o processo de democratização da Educação Superior no Brasil, pois em seu bojo oferta também Educação Superior (Bacharelados, Licenciaturas e cursos Tecnológicos), incluindo ainda cursos de pósgraduação tanto lato sensu, quanto stricto sensu no âmbito da Rede Federal de forma imbricada a Educação Profissional e Tecnológica (EPT).

O atendimento a Educação Superior nos Institutos Federais de Educação, Ciência e Tecnologia (IF's) possuem embasamento legal, a partir do Art. $2^{\circ}$ da Lei $n^{\circ} 11.892 / 08$ no que se refere a definição da instituição como sendo responsável por diferentes modalidades de educação pela perspectiva da Educação Profissional e Tecnológica em âmbito Federal, destacando ainda como essa nova institucionalidade é equiparada a universidades no que tange a regulamentação, avaliação e supervisão desta instituição. Esta perspectiva torna-se mais clara ao observarmos o Art. $6^{\circ}$, parágrafo III da referida lei, no que se refere as finalidades e características dos Institutos Federais: "promover a integração e a verticalização da educação básica à educação profissional e educação superior, otimizando a infraestrutura física, os quadros de pessoal e os recursos de gestão" e no Art. $7^{\circ}$, parágrafo VI no que se refere aos seus objetivos "ministrar em nível de educação superior".

Art. 2ํㅡㅁ Institutos Federais são instituições de educação superior, básica e profissional, pluricurriculares e multicampi, especializados na oferta de educação profissional e tecnológica nas diferentes modalidades de ensino, com base na conjugação de conhecimentos técnicos e tecnológicos com as suas práticas pedagógicas, nos termos desta Lei.

$\S 1^{\underline{0}}$ Para efeito da incidência das disposições que regem a regulação, avaliação e supervisão das instituições e dos cursos de educação superior, os Institutos Federais são equiparados às universidades federais. 
Neste cenário temos então uma nova institucionalidade, que articula em seus processos a Educação Superior junto a perspectiva da Educação Profissional e Tecnológica (EPT), é preciso que está articulação já é executada em no Brasil desde 1968 (Lei nº 5540/68) com a criação dos cursos Superiores de Tecnologia (chamados então de Cursos Profissionais Superiores de Curta Duração). A Lei n ${ }^{\circ}$ 11.892/08 coloca os Institutos Federais de Educação, Ciência e Tecnologia (IF's) como agentes verticalizadores e propulsores de políticas públicas, pois essa nova institucionalidade acaba "abraçando" em seu conjunto uma série de níveis e modalidades de ensino, que de forma direta ou indireta acabam "influenciando" - de certa forma - as proposições da Educação Superior em seu interior. Dessa forma, compreender os processos e os mecanismos no qual se inserem a Educação Superior nesse contexto, é de extrema importância para o campo acadêmico, pois nos permite ao menos perceber de que forma está "nova" articulação busca alcançar junto as finalidades desta modalidade como preconiza a LDBEN, em seu Art. 43 (BRASIL, 1996), a saber:

I - estimular a criação cultural e o desenvolvimento do espírito científico e do pensamento reflexivo;

II - formar diplomados nas diferentes áreas do conhecimento, aptos para a inserção em setores profissionais e para a participação no desenvolvimento da sociedade brasileira, e colaborar na sua formação contínua.

III - incentivar o trabalho de pesquisa e investigação científica, visando o desenvolvimento da ciência e da tecnologia e da criação e difusão da cultura, e, desse modo desenvolver o entendimento do homem e do meio em que vive;

IV - promover a divulgação de conhecimentos culturais, científicos e técnicos que constituem patrimônio da humanidade e comunicar o saber através do ensino, de publicações ou de outras formas de comunicação;

$\mathrm{V}$ - suscitar o desejo permanente de aperfeiçoamento cultural e profissional e possibilitar a correspondente concretização, integrando os conhecimentos que vão sendo adquiridos numa estrutura intelectual sistematizadora do conhecimento de cada geração;

VI - estimular o conhecimento dos problemas do mundo presente, em particular os nacionais e regionais, prestar serviços especializados à comunidade e estabelecer com esta uma relação de reciprocidade; VII - promover a extensão, aberta à participação da população, visando à difusão das conquistas e benefícios resultantes da criação cultural e da pesquisa científica geradas na instituição.

As pesquisas compreendidas como Estado da Arte ou mesmo Estado do Conhecimento, podem ser definidas em função do seu caráter bibliográfico e o seu compromisso de mapear e trazer para o debate a produção acadêmica em diferentes campos do saber, possibilitando assim, a compreensão de aspectos e consequentemente as dimensões onde está produção bibliográfica se insere dentro do campo científico (FERREIRA, 2002, p. 257). O uso de Estados do Conhecimento na compreensão de fenômenos é relativamente novo no Brasil, sendo que algumas áreas (como a da Educação por exemplo) são as que mais aprofundaram seus estudos na tentativa de mapear a produção acadêmica de determinada área temática na busca de compreender a percepção que a comunidade de pesquisadores sobre o campo científico. É nessa perspectiva que trazemos para o debate a ideia das "pesquisas que estudam pesquisas" como define Slongo (2004, p. 21), este movimento investigativo se 
coloca como um fenômeno fundamental para a compreensão do saber científico nas mais diferentes áreas do conhecimento.

A realização de pesquisas que possuem como fundamento esta perspectiva de construção de Estados do Conhecimento, utilizam-se do rigor científico do procedimento metodológico a sua validação, em linhas gerais, para a realização de pesquisas sobre pesquisas a partir de bases de dados é necessário: definir os descritores da busca (palavraschaves) a fim de direcionar os achados; localizar os bancos de dados (acervos) onde será capturado o material bibliográfico a ser analisado; definir os critérios de seleção para o material bibliográfico componente do corpus de análise; a leitura do corpus de analise buscando a elaboração de uma síntese preliminar deste material (tendo em vista os objetivos da construção do estado do Conhecimento de determinado tema) e por fim, sistematizar esses achados identificando possíveis tendências dos temas abordados a partir do processo de categorização (ROMANOWSKI, 2002, p.15-16).

Morosini e Fernandes (2014, p. 154) complementam as ideias trazidas por Ferreira (2002), Slongo (2004) e Romanowski (2002), sobre a percepção na construção dos Estados do Conhecimento, partindo da percepção deste processo como uma alternativa no entendimento dos contextos em que se inserem as pesquisas, as autoras traduzem está "metapesquisa" como sendo o momento onde o pesquisador sistematiza o conhecimento produzido anteriormente pelos seus pares, pois - como coloca Morosini (2015, p. 102) parte da "identificação, registro, categorização que levem à reflexão e síntese sobre a produção científica de uma determinada área, em um determinado espaço de tempo", considerando ainda que:

(...) faz-se necessário considerar que a construção de uma produção científica está relacionada não só à pessoa/pesquisador que a produz, mas a influências da instituição na qual está inserida, do país em que vive e de suas relações com a perspectiva global. Em outras palavras, a produção está inserida no campo científico e, consequentemente, em suas regras constitutivas (MOROSINI, 2015, p. 102).

E é justamente nesse sentido que buscamos compreender a forma que se dá o processo de produção acadêmica junto a temática da Educação Superior no conjunto dos Institutos Federais de Educação, Ciência e Tecnologia (IF's). A luz da utilização de princípios de Estado do Conhecimento e ainda "tentando identificar que aspectos e dimensões vêm sendo destacadas e privilegiadas em diferentes épocas e lugares" (FERREIRA, 2002, p. 258), buscamos com este estudo, identificar a produção acadêmica desenvolvida em Programas de Pós-Graduação brasileiros, dentro da temática da Educação Superior no conjunto dos Institutos Federais de Educação, Ciência e Tecnologia pelo viés da Gestão Educacional entre os anos de 2011 e 2016. A construção do entendimento desta identificação (categorias e subcategorias de análise), parte da utilização combinada dos contextos presentes junto a Abordagem do Ciclo de Políticas (BALL; BOWE; GOLD, 1992) e das diferentes, mas 
complementares dimensões da Gestão Educacional presentes no Paradigma Multidimensional da Administração Educacional (SANDER, 2007).

Ambas as perspectivas teóricas apresentadas por Ball, Bowe e Gold (1992) e Sander (2007), se colocam junto ao campo da Gestão Educacional sob uma perspectiva que leva em consideração os diferentes momentos e contextos que as políticas educacionais nos diferente níveis e modalidades se efetivam, como é o caso da Educação Superior implementada nos Institutos Federais de Educação, Ciência e Tecnologia (IF's), como aponta Pacheco (2011) ao se referir ao papel desta nova institucionalidade no contexto da Educação Profissional e Tecnológica (EPT). Acreditamos ainda que a abordagem adotada por este estudo junto ao entendimento da temática da Educação Superior, acaba por trazer consideração interessantes para o campo de estudo, já que coloca em perspectiva novas possibilidades de articulação e entendimento da Educação Superior à luz dos processos de Gestão Educacional, especialmente para aqueles advindos que se efetivam a partir de contextos emergentes.

\section{ESTRATÉGIAS METODOLÓGICAS NA CONSOLIDAÇÃO DO ESTUDO}

Da mesma forma que Minayo (2000, p. 16), compreendemos a metodologia de trabalho como sendo "o caminho do pensamento e a prática exercida na abordagem da realidade", de forma a ter um lugar de destaque no cerne dos estudos produzidos, assumindo assim um papel indicativo/direcional, já que a sua escolha possui relação direta com os resultados esperados pelo pesquisador, pois não podemos deixar de registrar que o contexto da metodologia científica surge também como uma forma de validar a trajetória do processo investigativo no qual se insere o fenômeno estudado. Assim, iniciamos o trabalho para a construção do corpus de análise ${ }^{3}$ a partir de um estudo exploratório junto ao banco de Teses e Dissertações da Coordenação de Aperfeiçoamento de Pessoal de Nível Superior (CAPES), a fim de termos um panorama do que se produz dentro da área da Educação Superior na perspectiva dos Institutos Federais de Educação, Ciência e Tecnologia em nosso país, utilizamos como descritor da busca básica a expressão Educação Superior Institutos Federais.

Os dados para este estudo foram produzidos entre os meses de março e dezembro de 2016, com o recorte temporal abrangido pelos estudos publicizados entre os anos de 2011 e 2016. Foram elencadas bases de dados para a procura do corpus de análise, inicialmente apenas o Banco de Teses e Dissertações da CAPES, porém acreditamos que com a inclusão de outras bases de dados, como por exemplo os Bancos de Dissertações e Teses de Programas de Pós-Graduação em Educação brasileiros avaliados pela CAPES com notas 6 (seis) e 7 (sete), seria igualmente interessante, já que poderia abarcar trabalhos por ventura não listados

\footnotetext{
${ }^{3}$ Da mesma forma que Morosini e Fernandes (2014, p.156), entendemos aqui o corpus de análise, como sendo "constituído a partir de: livros - produção amadurecida; teses e dissertações - produção reconhecida junto aos órgãos de avaliação da produção nacional”.
} 
pelo Banco de Teses e Dissertações da CAPES. De forma a complementar as buscas, outras bases de dados foram consultadas: Biblioteca Digital Brasileira de Teses e Dissertações (BDTD) do Instituto Brasileiro de Informação em Ciência e Tecnologia; a Biblioteca Digital de Teses e Dissertações da UFMG (BDTD UFMG), Repositório Digital da Biblioteca da UNISINOS (RDBU UNISINOS), Biblioteca Digital de Teses e Dissertações PUCRS (BDTD PUCRS). Nesse contexto, a organização do corpus de análise, é definida a partir de 3 (três) momentos construtivos fundamentais: a Bibliografia Anotada, a Bibliografia Sistematizada e pôr fim a Bibliografia Categorizada seguindo as definições de Morosini e Nascimento (2015, p.3). Cada um destes momentos prioriza uma etapa da construção do corpus, pois permitem o aprofundamento/entendimento de cada um dos trabalhos que o constituem de forma a possibilitar o conhecimento do que, como, e onde a produção acadêmica da temática elencada se constitui.

A Bibliografia Anotada é o primeiro movimento necessário para a constituição do corpus de análise e começarmos a dar início ao processo metodológico, consiste então na seleção do material bibliográfico que irá compor o que nominamos de Banco de Dados da Educação Superior nos Institutos Federais (BDESIF's), este banco é composto de todos os trabalhos extraídos das bases de dados consultadas. O objetivo desta fase é auxiliar o pesquisador na identificação e seleção dos materiais (Teses e Dissertações), dessa forma, é importante que algumas informações sejam registradas, como a data da busca bibliográfica, a base de dados consultada, os termos da busca utilizados, o total de trabalhos encontrados e o número de trabalhos efetivamente utilizados (aqueles estudos que de fato possuem relação direta com o temática de estudo na construção do Estado do Conhecimento), a referência completa desta bibliografia e o resumo do mesmo.

Seguindo o caminho metodológico, iniciamos o processo de elaboração da bibliografia sistematizada, esta etapa se coloca como o momento onde o pesquisador acaba aprofundando seu conhecimento sobre os materiais elencados e selecionados na etapa anterior. Após a leitura deste material, seguimos o processo de registro de informações, porém desta vez, detalhando ainda mais alguns aspectos, como o ano de defesa (no caso de teses e dissertações), o nível da produção acadêmica (mestrado ou doutorado), palavras-chave elencadas pelo autor, a metodologia utilizada no estudo e seus respectivos resultados. A escolha destes itens é arbitrária, pois acaba tendo como pano de fundo os objetivos do pesquisador na construção do Estado do Conhecimento, a partir das informações disponibilizadas no material bibliográfico que são relevantes para o pesquisador seguir em suas análises.

O processo de construção das bibliografias é extremamente dinâmico, na Bibliografia Anotada selecionamos o material bibliográfico a partir da leitura flutuante do material, dando destaque as informações colocadas junto aos títulos e os resumos. Já na próxima etapa, de forma mais aprofundada, compreendemos melhor o que material selecionado anteriormente, a 
partir de uma leitura mais atenciosa e criteriosa de outros itens (como os objetivos e a metodologia), o que nos permite - quando necessário - retirar algum material de nossa seleção, pois percebemos que o mesmo acaba não condizendo com o corpus levantado na construção do Estado do Conhecimento. Ao final, dessas etapas podemos - inicialmente compor um quadro que sistematize os primeiros achados, de forma clara, simples e direta (tabela 1). Dispomos algumas informações referentes a trajetória metodologia executada até este momento da pesquisa, como os tipos de busca realizadas, as bases de dados consultadas, os descritores (palavras-chaves) utilizados na captação do material bibliográfico, os parâmetros de busca (refinamento na captura do material a partir da base de dados utilizada) e o número total de trabalhos encontrados na busca e aqueles que selecionamos para a composição do corpus de análise do banco de dados.

Tabela 1. Sistematização do corpus de análise do BDESIF's a partir das Bibliografias Anotada e Sistematizada.

\begin{tabular}{|c|c|c|c|c|}
\hline $\begin{array}{l}\text { TIPO DE } \\
\text { BUSCA }\end{array}$ & $\begin{array}{l}\text { DESCRITORES } \\
\text { UTILIZADOS }\end{array}$ & $\begin{array}{l}\text { PARÂMETROS } \\
\text { DE BUSCA }\end{array}$ & $\begin{array}{l}\text { TRABALHOS } \\
\text { ENCONTRADOS }\end{array}$ & $\begin{array}{c}\text { TRABALHOS } \\
\text { SELECIONADOS }\end{array}$ \\
\hline \multirow{2}{*}{ Básica } & $\begin{array}{l}\text { Educação Superior nos } \\
\text { Institutos Federais }\end{array}$ & GERAL & 31 & 11 \\
\hline & $\begin{array}{l}\text { Ensino Superior } \quad \text { nos } \\
\text { Institutos }\end{array}$ & GERAL & 10 & 4 \\
\hline Avançada & $\begin{array}{c}\text { Gestão Educacional } \\
+ \\
\text { Educação Superior } \\
+ \\
\text { Institutos Federais }\end{array}$ & $\begin{array}{l}\text { Resumo } \\
\text { Palavras-Chave }\end{array}$ & 5 & 3 \\
\hline \multirow{4}{*}{$\begin{array}{l}\text { OUTRAS } \\
\text { BASES DE } \\
\text { DADOS }\end{array}$} & \multirow{4}{*}{$\begin{array}{c}\text { Gestão Educacional } \\
+ \\
\begin{array}{c}\text { Educação Superior } \\
+\end{array} \\
\text { Institutos Federais }\end{array}$} & IBICT & 17 & 10 \\
\hline & & $\begin{array}{l}\text { Biblioteca Digital de } \\
\text { Teses e Dissertações } \\
\text { da UFMG (BDTD } \\
\text { UFMG) }\end{array}$ & 46 & 2 \\
\hline & & $\begin{array}{l}\text { Repositório Digital } \\
\text { da Biblioteca da } \\
\text { UNISINOS (RDBU } \\
\text { UNISINOS) }\end{array}$ & 28 & 2 \\
\hline & & $\begin{array}{l}\text { Biblioteca Digital de } \\
\text { Teses e Dissertações } \\
\text { PUCRS } \\
\text { PUCRS) }\end{array}$ & 56 & 4 \\
\hline \multicolumn{3}{|c|}{ TOTAL DE TRABALHOS NO BDESIF'S } & 193 & 36 \\
\hline
\end{tabular}

Fonte: os autores.

E pôr fim, iniciamos o processo de construção da Bibliografia Categorizada, esta etapa consiste em separamos o corpus de análise a partir de categorias que nos auxiliem na interpretação do material bibliográfico que acaba compondo o banco de dados. Essas categorias podem surgir de 2 (duas) formas: podem surgir de forma "espontânea", onde ao 
observar o conjunto de dados produzidos, os mesmos acabam indicando possíveis ligações/aglomerados, chamamos esta possibilidade de construção de categoria a posteriori. No caso deste estudo, optamos em utilizar categorias de análise já conhecidas dentro do campo científico, "categorias prontas", a priori, na tentativa de compreender o material bibliográfico a ser analisado. A escolha entre categorias a posteriori e a priori são prerrogativas do pesquisador, acreditamos que a sua escolha está ligada a natureza do estudo e aos objetivos do pesquisador. Neste estudo, as categorias a priori se colocam como uma nova possibilidade no entendimento da Educação Superior implementada no contexto dos Institutos Federais de Educação, Ciência e Tecnologia (IF's).

\section{O PROCESSO DE CATEGORIZAÇÃO: ESCOLHAS TEÓRICAS BALIZADORAS DO ESTUDO}

Dentro da abordagem teórico-metodológico adotada neste estudo, se insere a construção do Estado do Conhecimento da Educação Superior no conjunto dos Institutos Federais de Educação, Ciência e Tecnologia (IF's), a luz dos contextos e das dimensões da Gestão Educacional. Como colocado anteriormente, optamos por utilizar categorias previamente conhecidas, categorias de análise utilizadas na busca do entendimento dos diferentes contextos em que se inserem as políticas públicas e educacionais descritas Ball, Bowe e Gold (1992), transpostas por Mainardes (2006), e também as diferentes dimensões que se inserem os processos e os modelos de Gestão Educacional implementados no Brasil a luz do caminho percorrido pelas instituições, como levantou Sander (2007).

Utilizamos como embasamento teórico na construção das categorias de análise, o trabalho de Bowe, Ball e Gold (1992) e posteriormente de Ball (1994) no que se refere a construção da Policy Cycle Approach ou "Abordagem do Ciclo de Políticas". Para os autores as políticas educacionais ${ }^{4}$ se constituem a partir de diferentes momentos/contextos em que se inserem. O primeiro contexto é o Contexto de Influência, o ponto de partida, neste momento. As políticas são iniciadas e os discursos políticos à sua volta são estabelecidos, diferentes grupos disputam (dentro da arena) os fatores que irão influenciar a definição das finalidades sociais da política, os discursos por sua vez acabam ganhando legitimidade formando a base desta política. Temos também o Contexto da Produção do Texto, o momento onde os textos da política são constituídos e articulados (muitas vezes) com a linguagem do interesse público, tendo como base os acordos firmados no contexto anterior. Por fim, os textos políticos acabam representando, de certa forma a própria política e pensar

\footnotetext{
${ }^{4}$ Utilizamos a percepção da política pública nas etapas metodológicas, entendendo que a Educação Superior dentro dos Institutos Federais de Educação, Ciência e Tecnologia (IF's) surgem justamente como este foco, na busca por equidade e justiça social, conceitos estes imbricados a ideia de política pública. A Lei $\mathrm{n}^{\circ} 11.892 / 08$ acaba por deixar claro em seu Art. $2^{\circ}$ a definição deste espaço educativo como sendo uma instituição de educação superior, básica e profissional, pluricurriculares e multicampi, especializados na oferta de educação profissional e tecnológica nas diferentes modalidades de ensino, com base na conjugação de conhecimentos técnicos e tecnológicos com as suas práticas pedagógicas.
}

\begin{tabular}{l|l|l|l} 
(C) Rev. Inter. Educ. Sup. & Campinas, SP & v.3 & n.
\end{tabular}

\begin{tabular}{l|l} 
p.167-185 & jan./abr. 2017
\end{tabular}

ISSN 2446-9424 
na forma como esta política é implementada e muitas vezes (re)significada pelos sujeitos, cabe ao Contexto da Prática, no qual percebe-se os efeitos e as consequências da implementação de determinada política, muitas vezes contrários aos objetivos descritos originalmente pela política (MAINARDES, 2006, p. 98).

Em função da complexidade no qual se insere o tema de estudo, percebemos que apenas os contextos de Ball, Bowe e Gold (1992), e Ball (1994) não dariam conta especificidades dos trabalhos que compunham nosso corpus de análise, optamos em complementar a categorização com a utilização de subcategorias transpostas dos estudos de Sander (2007) a partir das dimensões basilares do Paradigma Multidimensional da Administração da Educação. Estas dimensões se efetivam a partir da relação entre a Gestão Educacional e as práticas articuladas, desenvolvidas e implementadas nos processos educativos. São respectivamente: a Dimensão Econômica, a Dimensão Pedagógica, a Dimensão Política e a Dimensão Cultural, que correspondem cada uma, ao seu respectivo critério administrativo: Eficiência, Eficácia, Efetividade e Relevância ${ }^{5}$.

O campo da Educação Superior possui uma complexidade tamanha, já que se articula com uma série de questões de natureza social, metodológica, administrativa, entre tantas outras, de qualquer forma, inspirados pelo trabalho de Mainardes (2016) em utilizar a perspectiva da teorização combinada no entendimento de fenômenos, acreditamos que este recurso seria de grande valia na construção deste Estado do Conhecimento. A utilização da teorização combinada se faz presente em nosso estudo a partir das grandes categorias analíticas utilizadas por Ball e colaboradores (1992) no uso da Abordagem do Ciclo de Políticas e Sander (2007) a partir da perspectiva do Paradigma Multidimensional da Administração da Educação.

(...) a teorização combinada é um esforço de articular teorias ou conceitos oriundos de diferentes teorias, com o objetivo de compor um quadro teórico consistente para fundamentar uma determinada análise. Tal esforço demanda fazer escolhas teóricas e justificá-las, o que implica em um exercício de reflexividade e de vigilância epistemológica (MAINARDES, 2016, p. 4).

$\mathrm{Na}$ categoria Contexto da Influência, alocamos a subcategoria da Dimensão Econômica, esta dimensão tem como característica marcante a forma como os processos de gestão educacional se desenvolvem a partir do "envolvimento de recursos financeiros e materiais, estruturas, normas burocráticas e mecanismos de coordenação e comunicação" como define Sander (2007, p. 96). A categoria Contexto da Produção do Texto, relacionase com a subcategoria Dimensão Política, já que esta dimensão pode ser traduzida como a organização das ações estratégicas da instituição de ensino, para Sander (2007, p. 98) essa dimensão é extremamente importante pois é nela que estão "radicalizadas as

\footnotetext{
5 Para Sander (2007), a eficiência é subsumida pela eficácia; a eficácia e a eficiência são subsumidas pela efetividade; e a efetividade, a eficácia e a eficiência são subsumidas pela relevância" (SANDER, 2007, p.106).

\begin{tabular}{l|l|l|l|l|l|l} 
(C) Rev. Inter. Educ. Sup. & Campinas, SP & v.3 & n.1 & p.167-185 & jan./abr. 2017 & ISSN 2446-9424 \\
\hline
\end{tabular}
}


responsabilidades sociais das organizações educacionais. Na categoria Contexto da Prática, alocamos 2 (duas) subcategorias: a Dimensão Pedagógica que se coloca junto ao "o conjunto de princípios, cenários e técnicas educacionais, intrinsecamente comprometidas com a consecução eficaz dos objetivos escolares”, como coloca Sander (2007, p. 97); e a Dimensão Cultural sendo aquela responsável pela valorização das crenças e atitudes presentes no espaço educativo, compartilhadas e significadas a partir da presença da comunidade envolvida com a instituição de ensino, como aponta Sander (2007, p. 99).

No momento de aglutinarmos as categorias e as subcategorias, buscamos seus principais elementos característicos/definidores, de forma que a aproximação de ambas não ocorresse de forma forçada ou até mesmo incoerente, nesse sentido, buscamos entre os teóricos suas convergências como elo facilitador desta combinação. Percebemos que ambos teóricos acabam por adotar uma perspectiva holística dos processos desenvolvidos nas instituições de ensino (nas diferentes etapas e nos diferentes níveis de ensino) na efetivação de sua atividade fim, tendo ainda a Gestão Educacional situada em um tempo e em um contexto específico, demarcado e repleto de influencias.

O Contexto da Influência, é o momento onde as políticas são pensadas (ou ainda planejadas), sofrendo constantes pressões dos diferentes setores no qual se focalizam. Segundo Ball (2014) é pelo viés econômico que as políticas educacionais, em grande parte, começam a ser pensadas pelos governantes, pois será a partir da economia que a sua implementação será estruturada. O Contexto da Produção do Texto refere-se as possibilidades descritas nos textos legais na concretização das políticas educacionais, e para isso o campo da política propriamente dita é a arena onde os embates ocorrem, já que os textos legais acabam expressando a vontade política. O Contexto da Prática é a política colocada na perspectiva do sujeito, de forma a ser por muitos "modificada", ou melhor, (re)significada, e nesse sentido que Sander (2007) traz como fundamental na compreensão da gestão na contemporaneidade, os saberes advindo das diferentes culturas e círculos que esses sujeitos de inserem, na promoção da qualidade de vida; e da mesma forma que a pedagogia se reinventa, pois acaba recebendo a missão de "preservar" a instituição educacional do contexto meramente econômico.

\section{NOVOS OLHARES PARA O CAMPO DA EDUCAÇÃO SUPERIOR NOS INSTITUTOS FEDERAIS A PARTIR DA PRODUÇÃO ACADÊMICA}

O Estado do Conhecimento da Educação Superior na Perspectiva dos Institutos Federais pelo viés da Gestão Educacional é composto por 36 (trinta e seis) estudos, divididos em 3 (três) categorias e 4 (quatro) subcategorias respectivamente: na categoria Contexto da Influência onde estão alocados os estudos que tem por vertente compreender os aspectos que influenciaram a criação de cursos, programas e até mesmo projetos no contexto da Educação Superior nos Institutos Federais, temos como subcategoria a Dimensão Econômica com 4 (quatro) estudos; já a categoria Contexto da Produção do Texto, que está direcionado quase que exclusivamente estudos que se debrucem sobre os textos e marcos legais da Educação Superior nesta nova institucionalidade, alocamos a subcategoria Dimensão Política no qual

\begin{tabular}{l|l|l|l|l|l|l|} 
(C) Rev. Inter. Educ. Sup. & Campinas, SP & v.3 & n.1 & p.167-185 & jan./abr. 2017 & ISSN 2446-9424
\end{tabular}


temos 8 (oito) estudos; na categoria Contexto da Prática reunimos estudos que tenham como foco a efetivação da Educação Superior no conjunto dos Institutos Federais a partir das práticas desenvolvidas em seu interior e as vivências dos sujeitos que se fazem presente dentro do espaço educativo, temos 2 (duas) subcategorias, respectivamente, Dimensão Cultural - com 11 (onze) estudos e Dimensão Pedagógica - com 13 (treze) estudos (tabela 2).

Tabela 2. Categorização do Banco de Dados da Educação Superior nos Institutos Federais (BDESIF's) pelo viés da Gestão Educacional a luz dos contextos da Abordagem do Ciclo de Políticas (BALL, 1994) e as dimensões do Paradigma Multidimensional da Administração da Educação (SANDER, 2007).

\begin{tabular}{l|l|c|c}
\multicolumn{1}{c}{ CATEGORIAS } & \multicolumn{1}{c}{ SUB-CATEGORIAS } & \multicolumn{2}{c}{ TOTAL } \\
\cline { 3 - 5 } CONTEXTO DA INFLUÊNCIA & Dimensão Econômica & 4 & $\boldsymbol{\%}^{\mathrm{APR}}$ \\
\hline & SUBTOTAL DE TRABALHOS & $\mathbf{4}$ & $\mathbf{1 1}$ \\
\hline \multirow{2}{*}{ CONTEXTO DA PRODUÇÃO DO TEXTO } & Dimensão Política & 8 & 22 \\
\hline \multirow{2}{*}{ CONTEXTO DA PRÁTICA } & SUBTOTAL DE TRABALHOS & $\mathbf{8}$ & $\mathbf{2 2}$ \\
\hline \multirow{2}{*}{ TOTAL DE TRABALHOS DO BDESIF'S } & 13 & 36 \\
\hline & Dimensão Pedagógica & 11 & 31 \\
\cline { 2 - 5 } & Dimensão Cultural & $\mathbf{2 4}$ & $\mathbf{6 7}$ \\
\hline
\end{tabular}

Fonte: os autores.

O Contexto da Influência, a partir dos dados produzidos, aparentemente é o menos explorado nos estudos dos Programas de Pós-Graduação brasileiros entre os anos de 2011 e 2016, acreditamos que está "falta" de estudos esteja relacionada com o pouco tempo de existência dos Institutos Federais de Educação, Ciência e Tecnologia (IF's). Não podemos deixar de apontar que os Institutos Federais, como possibilidade de Ensino Superior são recentes, no contexto da Educação Brasileira, tendo em vista sua criação em 2008. O caminho entre a criação, a efetivação e a análise dos processos (Educação Superior), não é curto e de fácil trânsito, o que acreditamos que tenha um impacto significativo na tentativa de compreender esse fenômeno por parte da comunidade de pesquisadores inseridas nos Programas de Pós-Graduação.

Sander (2007, p. 77) acredita que a dimensão econômica, que se coloca junto a este contexto, apresenta-se de diferentes formas no interior das instituições, geralmente imbricadas com o(s) modelo(s) implementados de Gestão Educacional destes espaços, e esta dimensão por sua vez seria um primeiro movimento na tentativa de pensar a Educação Superior em nosso país. Ball (2014) aponta ainda que por mais importante que este aspecto seja emergente no interior das instituições de ensino, no campo acadêmico esta perspectiva fora superada, mas não esquecida, tanto que com a internacionalização, a globalização e a forma que o neoliberalismo se coloca frente as demandas da sociedade, a luz da Educação Superior, em alguns momentos acaba pautando-se por esta dimensão.

\begin{tabular}{l|l|l|l|l|l|l} 
(C) Rev. Inter. Educ. Sup. & Campinas, SP & v.3 & n.1 & p.167-185 & jan./abr. 2017 & ISSN 2446-9424
\end{tabular}


O Contexto da Produção do Texto, possui caráter essencialmente político, o texto que representa a política educacional em suas diversas facetas, e suas diferentes "variações" se constroem a partir do debate legislativo/político. A construção os documentos legais, por exemplo, são aspectos importantes na implementação das políticas, por isso são objeto de estudo constante, os documentos legais acabam por representar, em última instância, o pensamento político dominante em um determinado contexto sócio-histórico. A dimensão política no contexto da Educação Superior, se coloca de forma emergente no quantitativo do BDESIF's, representando o dobro da produção acadêmica frente ao Contexto da Influência. Essencialmente os estudos que se articulam nesta dimensão se detêm aos textos, pesquisas e marcos legais da Educação Superior brasileira e a Educação Profissional e Tecnológica sob a perspectiva da Lei $n^{\circ} 11.892 / 08$. Cabe destacarmos ainda que esta produção bibliográfica, acaba focalizando seus esforços sobre a obrigatoriedade de oferta de alguns cursos por parte dos Institutos Federais (Licenciaturas e Engenharias), Currículos Interdisciplinares e Projetos Pedagógicos de Curso (PPC).

Se observarmos a tabela 2, podemos perceber que a maioria dos trabalhos que compõem o BDESIF's acabam inseridos sob a categoria do Contexto da Prática, ou seja, acaba privilegiando estudos que buscam analisar, investigar, apontar e compreender (em sua maioria) os diferentes modelos de Educação Superior implementados nos Institutos Federais de Educação, Ciência e Tecnologia (IF's), a partir da forma como a mesma e (re)significada pelos sujeitos. Nesse sentido, emergem 2 (duas) dimensões inseridas nesse contexto: a Dimensão Pedagógica e a Dimensão Cultural, com respectivamente 36\% (trinta e seis) e 31\% (trinta e um) dos trabalhos. Os estudos acabam centrando-se na percepção da Educação Superior a partir da sua articulação direta com os resultados obtidos a partir do atendimento das demandas educacionais da comunidade acadêmica no qual se insere. A comunidade de pesquisadores, nos últimos 5 (cinco) anos, acabou focalizando suas atenções na forma como os processos relacionados a Gestão da Educação Superior se articulam no atendimento das necessidades e também na diversidade dos sujeitos foco dos processos educacionais desenvolvidos na Educação Superior presente neste novo contexto emergente que entendermos ser os Institutos Federais de Educação, Ciência e Tecnologia.

Um outro aspecto que nos chamou a atenção no desenvolvimento deste estudo, é o aparente "desinteresse" da comunidade acadêmica nas investigações que versem sobre os processos que envolvem a Educação Superior e a Gestão Educacional nos/dos Institutos Federais de Educação, Ciência e Tecnologia, como podemos acompanhar pelo gráfico 1. Logo no início do período no qual abrange este estudo (2011), percebe-se que a produção acadêmica, em relação ao todo, é significativa no que se refere ao seu quantitativo, com um total de 8 (oito) trabalhos, com destaque aos estudos advindos do Mestrado Acadêmico com 6 (seis) produções. No ano subsequente (2012), iniciou-se o processo de crescimento da produção acadêmica dos cursos de Mestrado Acadêmico e Profissional - respectivamente 7 (sete) e 2 (dois) trabalhos, e um decréscimo aos estudos oriundos do doutoramento, onde os mesmos no período não se fizeram presentes, a produção deste período contou com 9 (nove) trabalhos em nível de Pós-Graduação, o maior volume de trabalhos encontrados no período analisado/compreendido por esse estudo (2011 - 2016). 


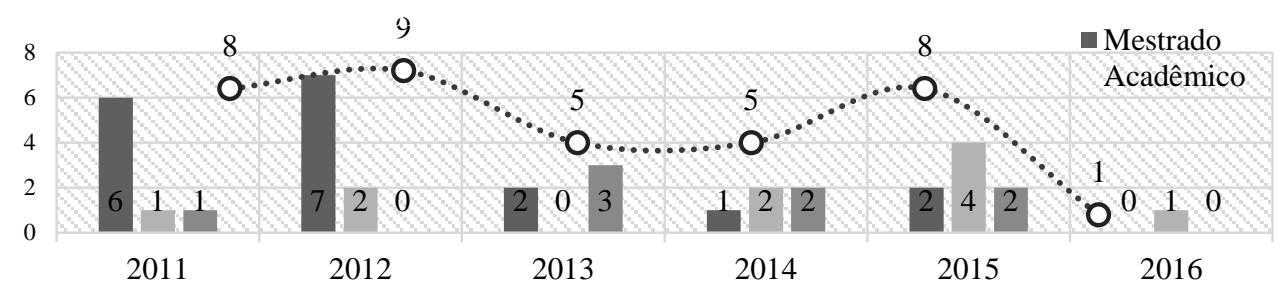

Gráfico 1. Distribuição da produção científica da temática da Educação Superior no conjunto dos Institutos Federais de Educação e Tecnologia entre os anos de 2011 e 2016 pelo viés da Gestão Educacional.

Fonte: Os autores.

Já em 2013, a produção acadêmica sobre a temática, passa por um período sensível, houve um decréscimo significativo na produção em relação ao ano anterior, chegando a representar cerca de $(55,5 \%)$ do total obtido no período anterior (2012), ou seja, 5 (cinco) trabalhos no período, pouco mais da metade. Por outra perspectiva, observamos que este ano se constitui como o ápice da produção acadêmica em nível de doutorado, 3 (três) trabalhos do total de 5 (cinco) produzidos no período. Posteriormente em 2014 a produção acadêmica se mantém estável, permanecendo com 5 (cinco) trabalhos elaborados durante o período, os cursos de Mestrado Acadêmico e Profissional com 3 (três) pesquisas desenvolvidas.

Em 2015 o cenário modifica-se, adotando novos contornos e a produção acadêmica emerge novamente com um aumento de $60 \%$ em relação ao ano de 2014 , com a marca de 8 (oito) pesquisas desenvolvidas sob a temática da Gestão da Educação nos Institutos Federais (IF's). Neste período, cabe destacarmos o quantitativo das produções do curso de Mestrado Profissional que totalizam 4 (quatro) do total produzido no ano, sua maior marca durante todo o espaço temporal que compõem este Estado do Conhecimento. Pôr fím, até o momento, identificamos a constituição da produção acadêmica do ano de 2016 a luz de 1 (um) estudo advindo do curso de Mestrado Profissional, demostrando assim o maior decréscimo da produção acadêmica dentro da temática nos últimos 5 anos. Acreditamos que em função das possíveis dificuldades de socialização dos estudos provenientes dos Programas de PósGraduação brasileiros, este número pode ser maior, de qualquer forma, até o momento que estes dados foram produzidos (entre os meses de março de 2016 e fevereiro de 2017), encontramos este número de trabalhos disponíveis nos repositórios e plataformas já mencionadas anteriormente.

Focalizando nosso olhar para as subcategorias de análise (gráfico 2), percebemos que os enfoques dados pelos estudos ao longo do tempo foram modificando-se de forma significativa neste período (2011 - 2016). Em 2011 os trabalhos produzidos pelos Programas de Pós-Graduação acabaram, majoritariamente focalizando seus estudos sobre Educação Superior a partir de 2 (dois) aspectos: a Educação Superior pensada pelo viés da efetivação dos seus princípios, objetivos e da sua missão junto a sociedade (Dimensão Pedagógica), não descartando as diferentes influências culturais no qual a Educação Superior sofre quando 
efetivada nos mais variados espaços (Dimensão Cultural), como é o caso das regiões onde estão inseridos os Institutos Federais de Educação, Ciência e Tecnologia.

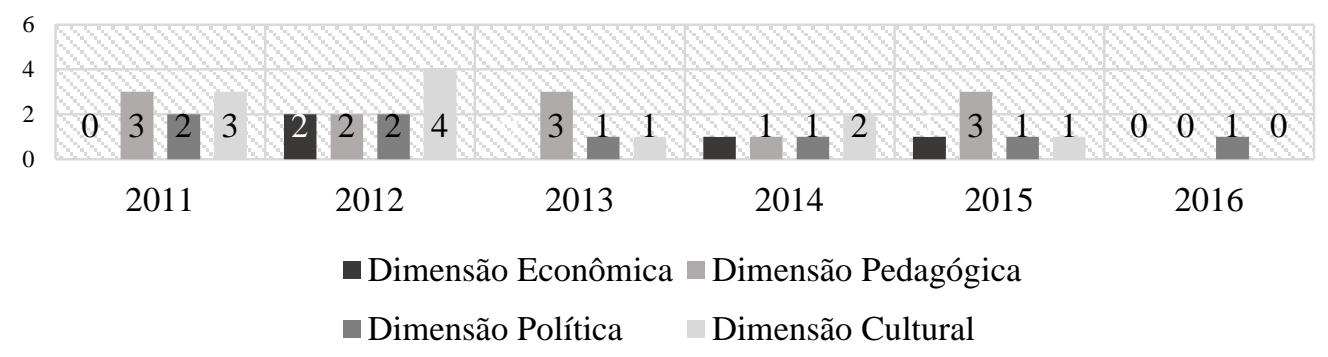

Gráfico 2. Distribuição da produção científica da temática da Educação Superior no conjunto dos Institutos Federais de Educação e Tecnologia entre os anos de 2011 e 2016 a partir das subcategorias de análise, pelo viés da Gestão Educacional.

Fonte: Os autores.

No ano seguinte (2012), os aspectos culturais continuam se fazendo presentes nas produções acadêmicas, em especial na forma como os arranjos locais se imbricam com os Cursos Superiores ofertados nas regiões onde os Institutos Federais de Educação, Ciência e Tecnologia (IF's) se instalavam. Em 2013 foi a vez da prevalência dos aspectos pedagógicos inseridos nos processos da Educação Superior, dando destaque ao currículo dos cursos no contexto da Educação Superior articulada Educação Profissional e Tecnológica (EPT). Nos anos de 2014 e 2015, os aspectos das culturais e pedagógicos, respectivamente, apareceram de forma mais marcante nas produções acadêmicas e em 2016 temos a preocupação da efetivação das políticas de Educação Superior em destaque (Dimensão Política).

Nos diferentes momentos históricos no qual se insere a compreensão deste estudo, as diferentes dimensões ou enfoques dentro do campo da Educação Superior no conjunto dos Institutos Federais (como demonstra o gráfico 2), se mostram de forma latente em função do seu quantitativo. Perceber este quantitativo trazido a partir da produção acadêmica se faz fundamental dentro do processo de produção de Estados de Conhecimento, pois o mesmo acaba dando indicativos de possíveis tendências dentro da própria produção do conhecimento. Nos gráficos 1 e 2, percebemos o quanto a produção acadêmica dos mestrados (tanto profissionais quanto acadêmicos) se sobressaem em comparação aos estudos de doutoramento. Dentro deste aspecto, temos um declínio expressivo da produção acadêmica nos mestrados acadêmicos, que se contrapõem a constância média de produção acadêmica dos mestrados profissionais.

\section{CONSIDERAÇÕES FINAIS}

A partir dos aportes teóricos utilizados na etapa de categorização deste estudo (Bibliografia Categorizada), foi possível construirmos um panorama sobre pesquisas que versam sobre a temática da Educação Superior no conjunto dos Institutos Federal pelo viés da Gestão Educacional. Entre os anos de 2011 e 2016, as pesquisas sobre a temática, tiveram 
como preocupação central, a forma como os processos de Gestão Educacional da Educação Superior se constituem a partir de um contexto prático, ou melhor, em um contexto de aplicação e efetivação dos processos gestionários desenvolvidos no interior dos Institutos Federais de Educação, Ciência e Tecnologia (IF's). Nesse sentido, o contexto da prática colocado como foco dos esforços da comunidade de pesquisadores, tem como marca aspectos pedagógicos relacionados aos processos de ensino-aprendizagem de docentes e discentes articulados a perspectiva da Educação Superior e a Educação Profissional e Tecnológica (EPT); e também aspectos relativos a inserção dos diferentes sujeitos da instituição a diferentes culturas, em particular a forma com que as peculiaridades dos diferentes grupos de sujeitos acabam influenciando processos de gestão implementados no interior da instituição.

A partir dos dados disponibilizados pelas bases de dados consultadas (Banco de Teses e Dissertações da CAPES, Biblioteca Digital de Teses e Dissertações da Universidade Federal de Minas Gerais (BDTD/UFMG), Repositório Digital da Biblioteca da Universidade do Vale dos Sinos (BDTD/UNISINOS), Biblioteca Digital de Teses e Dissertações da Pontifícia Universidade Católica do Rio Grande do Sul (BDTD/PUCRS) e do repositório Virtual do Instituto Brasileiro de Informação em Ciência e Tecnologia (BDTD/IBICT), conseguimos nos aproximar da produção acadêmica de Programas de Pós-Graduação brasileiros, o que nos permitiu vislumbrar as diferente facetas da Educação Superior a luz das categorias de análise (contextos e dimensões). Percebemos ainda, que existe um esforço por parte dos pesquisadores produtores desses estudos na superação de um modelo de Educação Superior pautado sob a ótica da eficiência econômica, levando em consideração outros aspectos, em especial aqueles de caráter pedagógico e cultural.

As dimensões culturais e pedagógicas acabam afirmando-se como fortes tendências no campo da Educação Superior relacionadas aos Institutos Federais de Educação, Ciência e Tecnologia, pois ambas aparecem de forma bastante consistente em todo o período analisado (2011 - 2016) e destacando-se dentre as demais dimensões (dimensão econômica e a dimensão política). Este aspecto corrobora o pensamento dos teóricos utilizados (BALL, 2014; SANDER, 2007), ambos compreenderem estes contextos e dimensões como sendo uma das principais preocupações da comunidade acadêmica na contemporaneidade. Nesse sentido, acreditamos que essas dimensões deveriam ser aprofundadas em estudos posteriores no campo da Educação Superior, já que estas categorias acabam alinhando-se a perspectiva da educação superior como política pública.

Se levarmos em consideração o contexto político no qual as atuais políticas de Educação Superior (por exemplo o Programa Universidade para Todos - PROUNI) se apresentam, esses contextos e estas dimensões acabam sendo de extrema relevância para o campo de estudo, pois de certo modo, são fundamentais na busca por um atendimento de excelência a sujeitos historicamente excluídos dos processos escolarizantes formais, além de 
trazer para a reflexão a Educação Superior e a Educação Profissional e Tecnológica nas diferentes esferas que se efetivam: aluno, professor e instituição.

O artigo aqui exposto, se colocou como um exercício de articulação da teorização combinada na tentativa de explicar o processo de produção do conhecimento dentro do campo científico que se insere a Educação Superior pelo olhar da Gestão Educacional. As próprias categorias analíticas trazidas pelos teóricos corroboram este fato, se levarmos em consideração o contexto no qual as produções dos teóricos se colocam como tentativas de compressão de fenômenos sociais relacionados aos processos educativos. Este estudo é um primeiro movimento de compreensão do tema a luz de novos referenciais teóricos, ou ainda, sob perspectivas atuais no entendimento dos processos de gestão inseridos no contexto global, um contexto repleto de influências tanto internas quanto externas, rodeado de pressões dos mais diferentes campos. O viés da Gestão Educacional surge como uma nova possibilidade no entendimento do fenômeno da Educação Superior emergente inserido em uma nova institucionalidade.

\section{REFERÊNCIAS}

BALL, S. J. Educação global S.A.: novas redes de políticas e o imaginário neoliberal. Tradução de Janete Bridon. Ponta Grossa: UEPG, 2014.

BALL, S. J. Educational reform: a critical and post-structural approach. Buckingham: Open University Press, 1994.

BOWE, R.; BALL, S.; GOLD, A. Reforming education \& changing schools: case studies in policy sociology. London: Routledge, 1992.

BRASIL. Lei nº 11.892, de 29 de dezembro de 2008. Institui a Rede Federal de Educação Profissional, Científica e Tecnológica, cria os Institutos Federais de Educação, Ciência e Tecnologia, e dá outras providências. Diário Oficial da União, Brasília/DF. Seção 1, ano CXLV, nº 253, 2008.

BRASIL. Lei n $^{\circ} 11.892$, de 29 de dezembro de 2008. Institui a Rede Federal de Educação Profissional, Científica e Tecnológica, cria os Institutos Federais de Educação, Ciência e Tecnologia, e dá outras providências. Diário Oficial da União, Brasília/DF. Seção 1, de 30 de dezembro de 2008. Brasília, DF, 2008.

BRASIL. Lei n ${ }^{\circ} 5.540$ de 28 de novembro de 1968. Fixa normas de organização e funcionamento do ensino superior e sua articulação com a escola média, e dá outras providências. Disponível em: <http://www.planalto.gov.br/ccivil_03/leis/L5540.htm>. Acesso em: 19 jan. 2017. 
BRASIL. Lei n ${ }^{\circ}$ 9.394, 20 de dezembro de 1996. Estabelece as diretrizes e bases da educação nacional. Disponível em http://www.planalto.gov.br/ccivil_03/leis/L9394.htm>. Acesso em: 12 fev. 2017.

CAVALCANTE, J. F. Educação superior: conceitos, definições e classificações. Brasília, DF: INEP, 2000.

FERREIRA, N. S. de A. As pesquisas denominadas "Estado da Arte". Educação \& Sociedade, Campinas, v. 23, n. 79, p. 257-272, ago. 2002.

MAINARDES, J. A abordagem do ciclo de políticas e suas contribuições para a análise da trajetória de políticas educacionais. Atos de Pesquisa em Educação, Blumenau, v.1, n. 2, maio/ago. 2006. Disponível em: <http://proxy.furb.br/ojs/index.php/atosdepesquisa/ article/view/34/10>. Aceso em: 19 jan. 2017.

MAINARDES, J. A produção do conhecimento em política educacional: análise de perspectivas teórico-epistemológicas e o lugar do pluralismo. In: CONGRESSO IBEROAMERICANO DE POLÍTICA E ADMINISTRAÇÃO DA EDUCAÇÃO, 5.; 2016, Goiânia.; CONGRESSO LUSO-BRASILEIRO DE POLÍTICA E ADMINISTRAÇÃO DA EDUCAÇÃO, 8.; 2016, Goiânia. Anais... Goiânia: [s.n.], 2016.

MINAYO, M. C. de S. Conceito de metodologia de pesquisa. In: MINAYO, M. C. S. (Org.). Pesquisa social: teoria, método e criatividade. 15.ed. Petrópolis: Vozes, 2000.

MOROSINI, M. C.; NASCIMENTO, L. M. Uma perspectiva metodológica da produção sobre Internacionalização da Educação Superior em programas de pós-graduação do Brasil. In: SEMINÁRIO INTERNACIONAL DE EDUCAÇÃO SUPERIOR, 8.; 2015, Porto Alegre. Anais... Porto Alegre, UFRGS, 2015.

MOROSINI, M. C. Estado de conhecimento e questões do campo científico. Educação (UFSM), Santa Maria, v. 40, n. 1, p. 101-116, jan./abr. 2015. Disponível em: <https://periodicos.ufsm.br/index.php/reveducacao/article/view/15822>. Aceso em: 19 jan. 2017.

MOROSINI, M. C.; FERNANDES, C. Estado do conhecimento: conceitos, finalidades e interlocuções. Educação Por Escrito. Porto Alegre: PUCRS, v. 5, n. 2, p.154-164. jul./dez. 2014. Disponível em: <http://revistaseletronicas.pucrs.br/ojs/index.php/porescrito/article/ view/18875>. Aceso em: 19 jan. 2017.

PACHECO, E. Institutos Federais: uma revolução na educação profissional e tecnológica. Brasília: Fundação Santillana; São Paulo: Editora Moderna, 2011.

ROMANOWSKI, J. P. Licenciaturas no Brasil: um balanço das teses e dissertações (19901998). 132 f. Tese (Doutorado em Educação) - Faculdade de Educação, Universidade de São Paulo - USP, São Paulo, 2002.

SANDER, B. Administração da educação no Brasil: genealogia do conhecimento. Brasília: Liber Livro, 2007. 
SANTOS, P. K. Abandono na educação superior: um estudo do tipo estado do conhecimento. Educação por Escrito, Porto Alegre, v. 5, n. 2, p. 240-255, jul./dez. 2014. Disponível em: $<$ http://revistaseletronicas.pucrs.br/ojs/index.php/porescrito/article/view/17896>. Aceso em: 19 jan. 2017.

SLONGO, I. I. P. A produção acadêmica em ensino de Biologia: um estudo a partir de teses e dissertações. 329 f. Tese (Doutorado em Educação) - Centro de Ciências da Educação, Universidade Federal de Santa Catarina - UFSC, Florianópolis, SC, 2004. 